Mahmood: Dynamic Analysis Of Bridges Subjected to Moving Vehicles

\title{
DYNAMIC ANALYSIS OF BRIDGES SUBJECTED TO MOVING VEHICLES
}

\author{
Dr. Mohamad Najim Mahmood \\ Assistant Professor \\ Ayad Thabit Saeed Al-Ghabsha \\ Assistant Lecturer \\ Civil Engineering Department / College of Engineering / University of Mosul
}

\begin{abstract}
In the present work the Finite Prism method was used for the dynamic analysis of bridges under moving vehicles. In this method a combination is used of the finite element method representing the cross section of the prism and Fourier series suitably chosen to represent the behavior of prism in the longitudinal direction, which satisfies the simply supported boundary conditions at the ends. Explicit time integration scheme was used for solving the equation of motion for each of the bridge and vehicle. In the present work damping was neglected in the formulation of equation of motion of bridges. These render to avoid the solution of global system of equations, because each equation becomes uncoupled with other equations. One of the main aspect in the present work is the coupling of the explicit solution technique of the equation of motion with the harmonic solution using the finite prism method for the problem of moving vehicle, taking into consideration the dynamic interaction between the vehicle and bridge.

Keywords: Bridge, Dynamic Interaction, Finite Prism, Moving Forces, Moving Vehicles
\end{abstract}

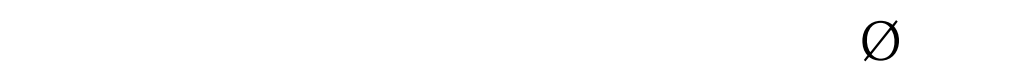

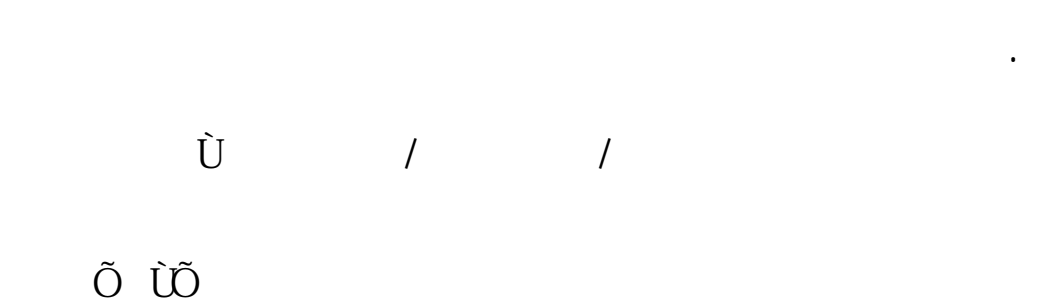

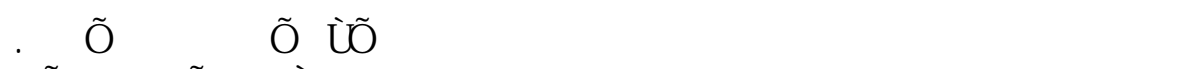

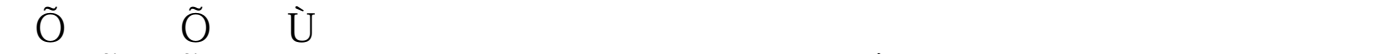

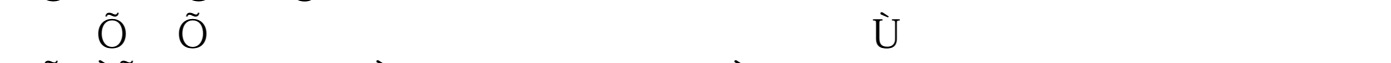

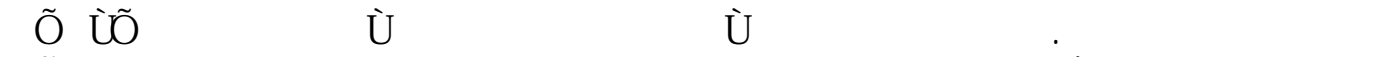

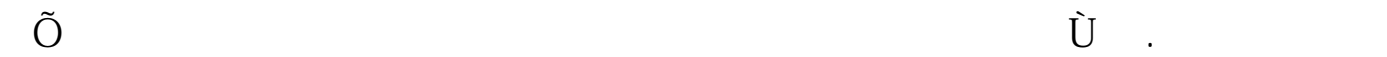

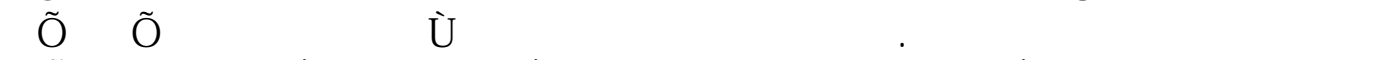

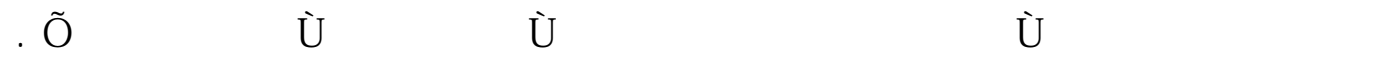

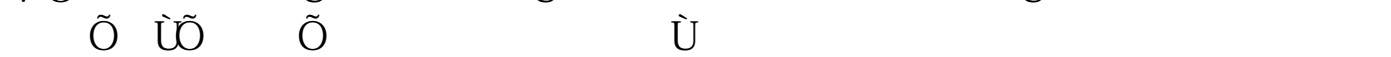

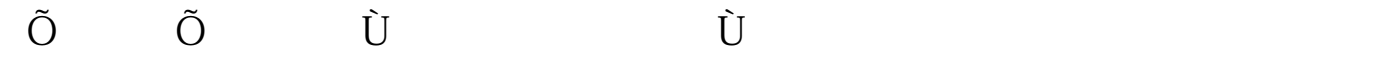

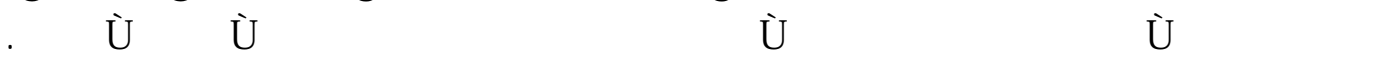




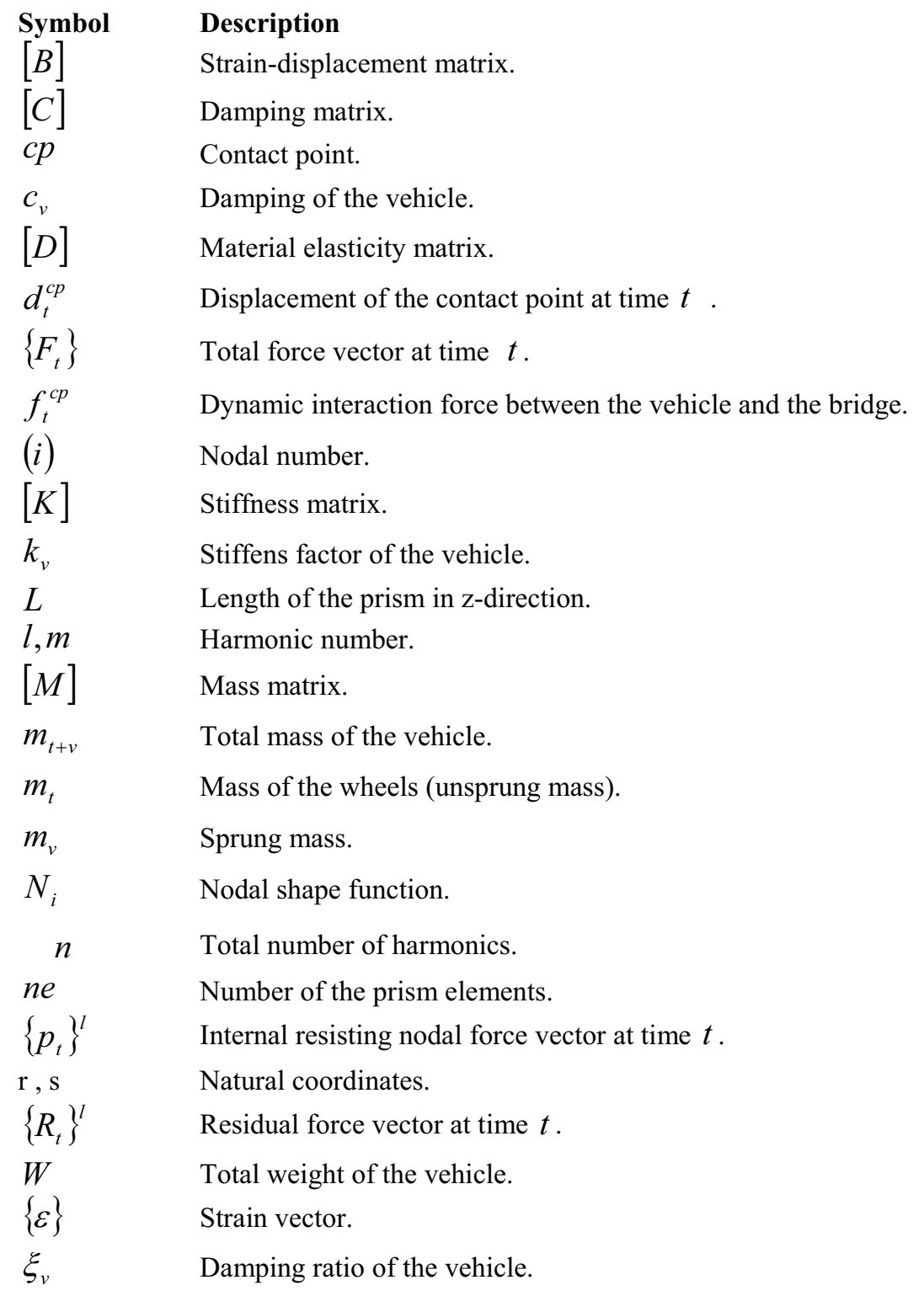

\section{Introduction}

The purpose of this work is to develop a procedure for obtaining the dynamic response of bridges subjected to moving vehicles. Naturally the bridges are threedimensional structures. The finite prism method which was first developed by Too [19] for the static analysis of bridges and also developed for the free vibration analysis of straight and curved deck and box girder bridges by AL - Darzi [1]. The same method is developed and used in the present work for the first time for the dynamic analysis of bridges due to moving vehicles. In this method a combination of 
the finite element method representing the cross section of the prism and Fourier series suitably chosen to represent the behavior of the prism in the longitudinal direction, and to satisfy the simply supported boundary conditions at the ends is used. In this method the three dimensional problem is reduced to a series of twodimensional one which are decoupled for each harmonic number. The explicit time integration scheme is used for solving the equation of motion for each of the bridge and vehicle. These afford avoiding the solution of global system of equations, because each equation becomes uncoupled with other equations. One of the main aspect in the present work is the coupling of the explicit solution technique of the equation of motion with harmonic solution using the finite prism method for the problem of moving vehicle taking into consideration the dynamic interaction between the vehicle and the bridge. Two models of vehicle have been used: In the first model, called the moving force model, the inertia force of the vehicle and the dynamic interaction between the vehicle and the bridge has been neglected. In the second model, called the moving vehicle model, the vehicle is represented by a spring mass system in which the inertia force of the vehicle and the dynamic interaction between the spring mass system and the vibration of the bridge is taking into consideration. The validity of the developed numerical model has been studied by analyzing structures such as simply supported plates and beams subjected to moving vehicles with different speeds, by using both models of vehicles. Comparison with the available reported results has shown an agreeable matching.

\section{Finite Prism Formulation}

The three dimensional displacement components can be written as:

$$
\{q\}=\left\{\begin{array}{l}
u \\
v \\
w
\end{array}\right\}
$$

where $u, v$ and $w$ are the displacements along the three dimensional Cartesian axes $\mathrm{X}$ , $\mathrm{Y}$ and $\mathrm{Z}$ respectively as shown in Figure (1):

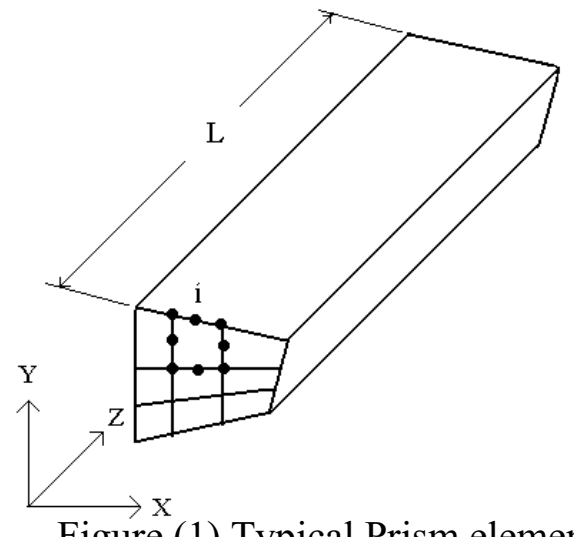

Figure (1) Typical Prism element. 
The displacement at any point in the eight-node prism element can be interpolated as follows $[1,19]$ :

$$
\begin{aligned}
& u(r, s, z)=\sum_{l=1}^{\infty} \sum_{i=1}^{n e} N_{i}(r, s) u_{i}^{l} \sin \frac{l \pi z}{L} \\
& v(r, s, z)=\sum_{l=1}^{\infty} \sum_{i=1}^{n e} N_{i}(r, s) v_{i}^{l} \sin \frac{l \pi z}{L} \\
& u(r, s, z)=\sum_{l=1}^{\infty} \sum_{i=1}^{n e} N_{i}(r, s) w_{i}^{l} \sin \frac{l \pi z}{L}
\end{aligned}
$$

where $u_{i}^{l}, v_{i}^{l}$ and $w_{i}^{l}$ are the nodal line displacements amplitudes for harmonic number $(l)$ at node $(i)$ for prism $(e),(n e)$ is the total number of nodal lines for the prism which is equal to eight, $\left(N_{i}\right)$ is the interpolation (shape) function in terms of the local coordinates $r, s$ which vary from -1 to +1 within the cross section of the prism.

The discretized expression for strains and stresses within an element can be expressed as [2]:

$$
\begin{aligned}
& \{\varepsilon\}=\sum_{l=1}^{\infty} \sum_{i=1}^{n e}\left[B_{i}^{l}\right]\left\{d_{i}^{l}\right\} \\
& \{\sigma\}=[D] \sum_{l=1}^{\infty} \sum_{i=1}^{n e}\left[B_{i}^{l}\right]\left\{d_{i}^{l}\right\}
\end{aligned}
$$

where $[D]$ is the elasticity matrix $[16]$ and the strain-displacement matrix $\left[B_{i}^{l}\right]$ associated with nodal line $(i)$ for the harmonic $(l)$ can be expressed as [1]:

$$
\begin{gathered}
{\left[B_{i}^{l}\right]=\left[\begin{array}{ccc}
\frac{\partial N_{i}}{\partial x} S l & 0 & 0 \\
0 & \frac{\partial N_{i}}{\partial y} S l & 0 \\
0 & 0 & -\frac{l \pi}{L} N_{i} \cdot S l \\
\frac{\partial N_{i}}{\partial y} S l & \frac{\partial N_{i}}{\partial x} S l & 0 \\
\frac{l \pi}{L} N_{i} \cdot C l & 0 & \frac{\partial N_{i}}{\partial x} C l \\
0 & \frac{l \pi}{L} N_{i} C l & \frac{\partial N_{i}}{\partial y} C l
\end{array}\right]} \\
\left\{d_{i}^{l}\right\}=\left[u_{i}^{l}, v_{i}^{l}, w_{i}^{l}\right]^{T}
\end{gathered}
$$

The strain and stress components in vector form can be written as: 


$$
\begin{aligned}
& \{\varepsilon\}=\left\{\varepsilon_{x}, \varepsilon_{y}, \varepsilon_{z}, \gamma_{x y}, \gamma_{x z}, \gamma_{y z}\right\}^{T} \\
& \{\sigma\}=\left\{\sigma_{x}, \sigma_{y}, \sigma_{z}, \tau_{x y}, \tau_{x z}, \tau_{y z}\right\}^{T}
\end{aligned}
$$

\section{Dynamic Equations}

The dynamic equation of motion of bridge can be expressed as:

$$
[M]\{\ddot{d}\}+[C]\{\dot{d}\}+[K]\{d\}=\left\{F_{t}\right\}
$$

where $[M],[C]$ and $[K]$ are the global mass, damping and stiffness matrices

respectively and $\{\ddot{d}\},\{\dot{d}\}$ and $\{d\}$ are the acceleration, velocity and displacement vectors respectively and $\left\{F_{t}\right\}$ is the external applied load, which is function of time t. The damping matrix can be written as $[3,18]$ :

$[C]=\int_{v}[N]^{T} c[N] d v$

Because of the orthogonality properties [1] i.e.;

$$
\left.\begin{array}{l}
\int_{0}^{L} \sin \frac{l \pi z}{L} \cdot \sin \frac{m \pi z}{L} d z \\
\int_{0}^{L} \cos \frac{l \pi z}{L} \cdot \cos \frac{m \pi z}{L} d z
\end{array}\right\}=0 \text { when } l=m
$$

Thus; the stiffness and mass matrices for harmonic $(l)$ can be written as:

$$
\begin{aligned}
& {\left[K_{i j}^{l l}\right]=\frac{L}{2} \iint_{A}\left[B_{i}^{l}\right]^{T}[D]\left[B_{j}^{l}\right] d x . d y} \\
& {\left[M_{i j}^{l l}\right]=\frac{L}{2} \iiint_{A}\left[N_{i}^{l}\right]^{T} \rho\left[N_{j}^{l}\right] d x . d y}
\end{aligned}
$$

The equivalent nodal force vector can be expressed as:

$$
\left\{F_{t}\right\}=\sum_{l=1}^{\infty} \sum_{i=1}^{n e}\left[\begin{array}{ccc}
N_{i} \cdot S l & 0 & 0 \\
0 & N_{i} \cdot S l & 0 \\
0 & 0 & N_{i} \cdot C l
\end{array}\right]\left\{f_{p}\right\}
$$

where $\left\{f_{p}\right\}$ is the vector of the applied concentrated force vector.

The integration of stiffness and mass matrices are carried out numerically using Gauss quadrature method. 


\section{Dynamic Interaction Between the Vehicle and the Bridge}

\section{Vehicle models}

The two vehicle models moving over the bridge are shown in Fig. (2). In the first model the vehicle is represented as a moving force in which the dynamic interaction between the vehicle and the bridge is neglected. In the second model, called the moving vehicle model, the vehicle is represented by a single degree of freedom system comprising sprung mass $\left(m_{v}\right)$ and unsprung mass $\left(m_{t}\right)$ with viscous damping $\left(c_{v}\right)$ included in the suspension, $\left(k_{v}\right)$ is the stiffness of the vehicles. It is assumed that the vehicle travels at constant velocity and that the unsprung wheel is always in contact with the road surface which is assumed to be smooth.

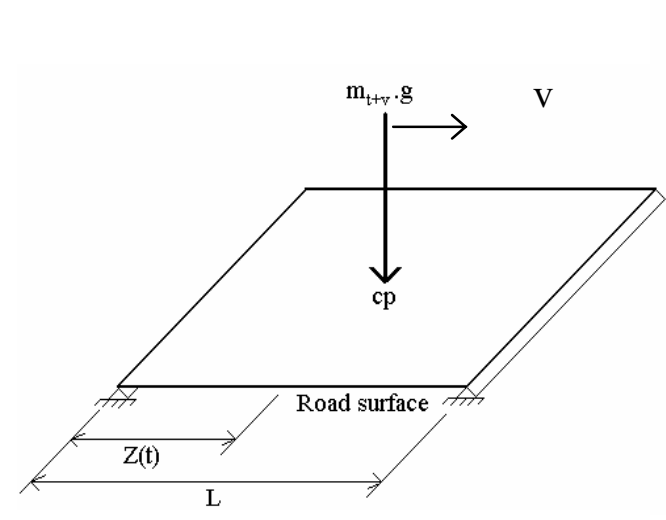

(a) Moving Force Model.

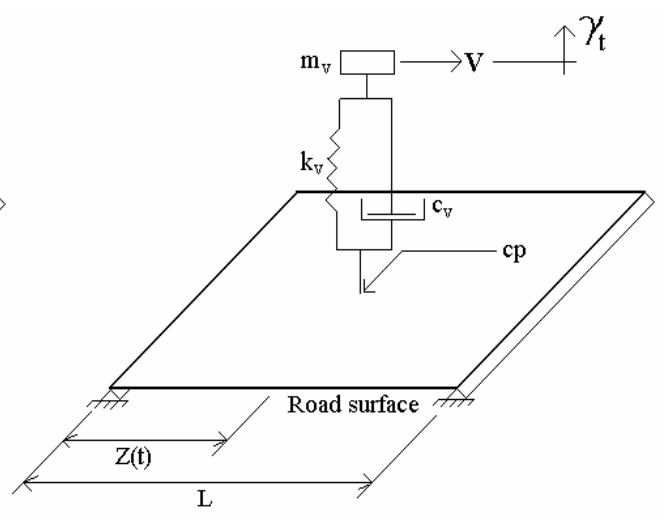

(b) Moving Vehicle Model.

Figure (2) Vehicle Models.

\section{Solution of Equation of Motion}

The integration of equation of motion (Eq. 9) is carried out using the explicit central difference scheme $[12,14]$. This is only applicable when the mass matrix is lumped mass matrix. This requires the transformation of constant mass matrix in (Eq.13) into a lumped mass matrix as in the following.

\section{Mass lumping}

The most simple method of lumping the prism mass matrix is by adding all terms of each line of the consistent mass matrix and placing the result on the diagonal, such a process gives the nodal masses in the form $[5,8]$ :

$$
\bar{M}_{i i}^{e}=\sum M_{i j}^{e}
$$

This method fails when applied to eight-node isoparametric element. The reason is that negative nodal masses are obtained in corner nodes. To overcome this, several 
alternative schemes have been investigated in the literature [8]. In the present work a new approach was developed in which the total mass of the element is divided equally between mid - side and corner nodes as:

$\bar{M}_{i i}^{e}=\frac{1}{8} M^{e}$

Another approach which is suggested by Owen and Hinton and by others [7,8,9,14], the mass is lumped to the diagonal terms of the consistent mass matrix in the form:

$$
\left.\begin{array}{l}
\bar{M}_{i i}^{e}=M_{i i}^{e}\left(\frac{M^{e}}{\sum M_{i i}^{e}}\right) \\
M_{i i}^{e}=\int_{v} N_{i}^{2} \rho d v
\end{array}\right\}
$$

where $M^{e}$ is the total mass of the element. This procedure is also used in the present work and both approaches gave almost same results.

\section{Explicit Time Integration Scheme}

The dynamic equation of motion for harmonic $(l)$ can be written at time $t$ as:

$$
[M]\left\{\ddot{d}_{t}\right\}^{l}+[C]\left\{\dot{d}_{t}\right\}^{l}+\left\{P_{t}\right\}^{l}=\left\{F_{t}\right\}^{l}
$$

where $\left\{P_{t}\right\}^{l}$ is the global vector of internal resisting nodal forces and $\left\{F_{t}\right\}^{l}$ is the vector of equivalent nodal forces resulting from the dynamic interaction force between the vehicle and bridge $f^{c p}$ at the contact point $c p$.

The dynamic interaction force $f^{c p}$ is a function of the displacement, velocity and acceleration at the contact point $d_{t}^{c p}, \dot{d}_{t}^{c p}$ and $\ddot{d}_{t}^{c p}$.

In the central difference approximation, the acceleration can be written as:

$$
\left\{\ddot{d}_{t}\right\}^{l}=\frac{1}{(\Delta t)^{2}}\left[\left\{d_{t+\Delta t}\right\}^{l}-2\left\{d_{t}\right\}^{l}+\left\{d_{t-\Delta t}\right\}^{l}\right]
$$

and the velocity may also expressed as:

$$
\left\{\dot{d}_{t}\right\}^{l}=\frac{1}{2(\Delta t)}\left[\left\{d_{t+\Delta t}\right\}^{l}-\left\{d_{t-\Delta t}\right\}^{l}\right]
$$

Substituting (19) and (20) in (18) and solving for $\left\{d_{t+\Delta t}\right\}^{l}$ yields: 


$$
\left\{d_{t+\Delta t}\right\}^{l}=\left([M]+\frac{\Delta t}{2}[C]\right)^{-1}\left[(\Delta t)^{2}\left\{R_{t}\right\}+2[M]\left\{d_{t}\right\}^{l}-\left([M]-\frac{\Delta t}{2}[C]\right)\left\{d_{t-\Delta t}\right\}^{\prime}\right]
$$

where $\left\{R_{t}\right\}^{l}$ is the residual force vector at time $\mathrm{t}$, which is equal to:

$$
\left\{R_{t}\right\}^{l}=\left\{F_{t}\right\}^{l}-\left\{P_{t}\right\}^{l}
$$

If the matrices $[M]$ and $[C]$ are both diagonal matrices then the solution of equation (21) for equation $i$ can be easily written as:

$$
\left(d_{i}\right)_{t+\Delta t}^{l}=\left(m_{i i}+\frac{\Delta t}{2} c_{i i}\right)^{-1}\left[(\Delta t)^{2}\left(r f_{i}\right)_{t}+2 m_{i i}\left(d_{i}\right)_{t}^{l}-\left(m_{i i}-\frac{\Delta t}{2} c_{i i}\right)\left(d_{i}\right)_{t-\Delta t}^{l}\right]
$$

where $\left(d_{i}\right)_{t+\Delta t}^{l}$ is the displacement in the $\mathrm{i}^{\text {th }}$ degree of freedom for harmonic number ( $l$ ). $m_{i i}$ and $c_{i i}$ are the corresponding diagonal terms of the mass and damping matrices, and $r f_{i}$ is the corresponding component of residual force vector.

\section{Starting Algorithm}

Since the governing equilibrium equation (23) or (21) involves information the previous time steps $t$ and $t+\Delta t$, therefore; a starting algorithm is required. Based on the initial conditions, the value at $0-\Delta t$ may be obtained from equation (20).

$$
\left(\dot{d}_{i}\right)_{0}^{l}=\frac{1}{2(\Delta t)}\left[\left(d_{i}\right)_{0+\Delta t}^{l}-\left(d_{i}\right)_{0-\Delta t}^{l}\right]
$$

from which

$$
\left(d_{i}\right)_{0-\Delta t}^{l}=-2 \Delta t\left(\dot{d}_{i}\right)_{0}^{l}+\left(\dot{d}_{i}\right)_{0+\Delta t}^{l}
$$

Substituting equation (25) in (23), the displacements of the $\mathrm{i}^{\text {th }}$ degree of freedom at the first time step $\Delta t$ for harmonic $(l)$ can be evaluated as:

$$
\left(d_{i}\right)_{\Delta t}^{l}=\frac{(\Delta t)^{2}}{2 m_{i i}}(r f i)_{0}^{l}+\left(d_{i}\right)_{0}^{l}+\Delta t\left[1-\frac{c_{i i} \Delta t}{2 m_{i i}}\right]\left(\dot{d}_{i}\right)_{0}^{l}
$$

It is reported in the literatures $[6,10,11,13]$, that the damping effect of the bridge is small and can be neglected in the analysis. The explicit algorithm is conditionally stable and it requires small time steps for accurate and stable solution. In the present work the estimation of critical time step given by Tsui and tony [17] was adopted. 


\section{Dynamic Condition at The Vehicle Contact Point}

The vertical displacement at the vehicle contact point $d_{t+\Delta t}^{c p}$ can be interpolated from the nodal displacement amplitudes at time step $t+\Delta t$, i.e. $\left\{d_{t+\Delta t}\right\}^{l}$ by using equation (2), also the velocity at the contact point at time step $t+\Delta t$ can be determined by backward finite difference scheme using the contact point displacement at time steps $t$ and $t+\Delta t$ as [2]:

$\dot{d}_{t+\Delta t}^{c p}=\frac{1}{\Delta t}\left[d_{t+\Delta t}^{c p}-d_{t}^{c p}\right]$

\section{Moving Vehicle Response and Interaction Force}

The nodal force vector due to moving vehicle at time step $t+\Delta t$ for each harmonic term $\left\{F_{t+\Delta t}\right\}^{l}$ consist of several terms. The nodal force due to the contact force between the vehicle and the bridge $f_{t+\Delta t}^{c p}$ can be determined for both vehicle models as follows:

\section{Moving force model}

For the moving force model in Figure (2 - a), the applied force on the bridge is due to the vehicle weight, which moves at constant speed, and its position is a function of time only. The force at the vehicle contact point can be calculated as:

$f_{t+\Delta t}^{c p}=-m_{t+v} \cdot g$

Then the nodal force vector for all harmonic numbers at time step $t+\Delta t$ can be calculated using equation (14) and the amplitude displacement for each harmonic at time step $t+\Delta t$ can be determined by equation (23).

\section{Moving vehicle model}

For the moving vehicle model shown in Figure (2 - b), the applied force on the bridge is due to the dynamic interaction between the vehicle and the bridge. The equation of motion for the moving vehicle model can be written as follows [2]:

$$
\begin{aligned}
& m_{t} \ddot{d}_{t+\Delta t}^{c p}+c_{v}\left(\dot{d}_{t+\Delta t}^{c p}-\dot{\gamma}_{t+\Delta t}\right)+k_{v}\left(d_{t+\Delta t}^{c p}-\gamma_{t+\Delta t}\right)=-m_{t} \cdot g \\
& m_{v} \ddot{\gamma}_{t+\Delta t}+c_{v}\left(\dot{\gamma}_{t+\Delta t}-\dot{d}_{t+\Delta t}^{c p}\right)+k_{v}\left(\gamma_{t+\Delta t}-d_{t+\Delta t}^{c p}\right)=-m_{v} \cdot g
\end{aligned}
$$

The displacement and velocity of the sprung mass at time step $t+\Delta t$ i.e. $\gamma_{t+\Delta t}$ and $\dot{\gamma}_{t+\Delta t}$ respectively can be determined depending on the known values of $d_{t+\Delta t}$ and $\dot{d}_{t+\Delta t}$ by solution of the equation of motion of the vehicle (29) using explicit time 
integration scheme. After a mathematical manipulation and simplification, the solution of $\gamma_{t+\Delta t}$ can be written as:

$\gamma_{t+\Delta t}=\frac{1}{\left(m_{v}+\frac{\Delta t}{c} c_{v}\right)}\left[(\Delta t)^{2}\left(R_{t}-k_{v} \gamma_{t}\right)+2 m_{v} \gamma_{t}-\left(m_{v}-\frac{\Delta t}{2} c_{v}\right) \gamma_{t+\Delta t}\right]$

where

$R_{t}=-m_{v} \cdot g+c_{v} \dot{d}_{t+\Delta t}^{c p}+k_{v} d_{t+\Delta t}^{c p}$

To calculate $\gamma_{\Delta t}$ at time $t=\Delta t$, the term $\gamma_{0-\Delta t}$ has to be known beforehand. So a starting algorithm is necessary and $\gamma_{\Delta t}$ can be determined as follows:

$\gamma_{\Delta t}=\frac{(\Delta t)^{2}}{2 m_{v}}\left(R_{0}-k_{v} \gamma_{0}\right)+\gamma_{0}+\Delta_{t}\left[1-\frac{c_{v} \Delta t}{2 m_{v}}\right] \dot{\gamma}_{0}$

The initial condition of the vehicle and the bridge at the contact point can be written as:

$d_{0}^{c p}=0, \dot{d}_{0}^{c p}=0, \ddot{d}_{0}^{c p}=0, \dot{\gamma}_{0}=0, \ddot{\gamma}_{0}=0$

By substituting these conditions in the previous equations, the initial value of $\gamma$ can be determined as:

$\gamma_{0}=\frac{-m_{v} \cdot g}{k_{v}}$

Then the interaction force at contact point at time step $t+\Delta t$ i.e. $f_{t+\Delta t}^{c p}$ can be determined as:

$f_{t+\Delta t}^{c p}=-\left(m_{t}+m_{v}\right) \cdot g-m_{v} \ddot{\gamma}_{t+\Delta t}-m_{t} \ddot{d}_{t+\Delta t}^{c p}$

Substituting equation (35) in equation (29 - b) yield:

$f_{t+\Delta t}^{c p}=-m_{t} \ddot{d}_{t+\Delta t}^{c p}+c_{v}\left(\dot{\gamma}_{t+\Delta t}-\dot{d}_{t+\Delta t}^{c p}\right)+k_{v}\left(\gamma_{t+\Delta t}-d_{t+\Delta t}^{c p}\right)-m_{t} \cdot g$

In view of the fact that the wheel mass $m_{t}$ is very small in comparison with the vehicle mass $m_{v}$, it can be neglected in equation (36), and accordingly this equation can be rewritten as:

$f_{t+\Delta t}^{c p}=c_{v}\left(\dot{\gamma}_{t+\Delta t}-\dot{d}_{t+\Delta t}^{c p}\right)+k_{v}\left(\gamma_{t+\Delta t}-d_{t+\Delta t}^{c p}\right)$ 
The velocity of the sprung mass $\dot{\gamma}_{t+\Delta t}$ can be calculated by using backward finite difference as:

$\dot{\gamma}_{t+\Delta t}=\frac{1}{\Delta t}\left[\gamma_{t+\Delta t}-\gamma_{t}\right]$

\section{Validation of the Method}

\section{Moving force model}

In order to confirm the accuracy of the developed numerical model, a simply supported plate at two opposite edges and subjected to a moving force, as shown in Figure (3) was first considered, and the plate cross section is divided into five prism elements. The information below gives details of the material properties and the moving force:

Moving force $=4.4482 \mathrm{~N}$

Force speed $=96.56 \mathrm{~km} / \mathrm{h}$

Modulus of elasticity $(\mathrm{E})=20684.4 \mathrm{MPa}$ (concrete)

Mass density $=2400 \mathrm{~kg} / \mathrm{m}^{3}$

Poisson's ratio $=0.15$

Plate thickness $=0.4572 \mathrm{~m}$

The dynamic response of this plate under a moving force is presented in terms of the normalized mid span displacements as shown in Figure (4). The normalized displacement at mid span is defined as "the ratio of the dynamic displacement at mid span to the maximum static displacement at mid span when the load at any point along the span". The present results are compared with those of Srinivasan and Munaswamy [15] using the finite strip method. Figure (4) shows the relation of the normalized displacement at the center of the plate with the normalized position of the vehicle along the span of the plate. It can be noticed from this figure that when the vehicle leaves the plate, the normalized displacement at the center of the plate is of the order $(0.16)$ which is due to the inertia force of the plate.

\section{Moving vehicle model}

A simply supported beam with the geometry shown in Figure (5) and subjected to a moving vehicle model has been analyzed. The beam cross section is divided into four prism elements. The details of the material properties and moving vehicle model is given below:

Modulus of elasticity $=22000 \mathrm{MPa}$ (concrete)

Mass density $=2400 \mathrm{~kg} / \mathrm{m}^{3}$

$m_{v}=1000 \mathrm{~kg}$

$c_{v}=8.54 \mathrm{~N} . \mathrm{sec} / \mathrm{mm}$

$k_{v}=292 \mathrm{~N} / \mathrm{mm}$

Span length $=5 \mathrm{~m}$ 
The analysis is carried out using five harmonic terms only. The predicted dynamic response is compared with that of Cai et al. [4] as shown in Figures (6) and (7). It can be noticed that by increasing the speed of the vehicle up to $(590.4 \mathrm{~km} / \mathrm{h})$, the maximum normalized displacement takes place when the vehicle is at about (0.7) of the span length, while when the vehicle moves at speed of $(295.2 \mathrm{~km} / \mathrm{h})$ the maximum normalized displacement takes place when the vehicle is at about (0.4) of the span.

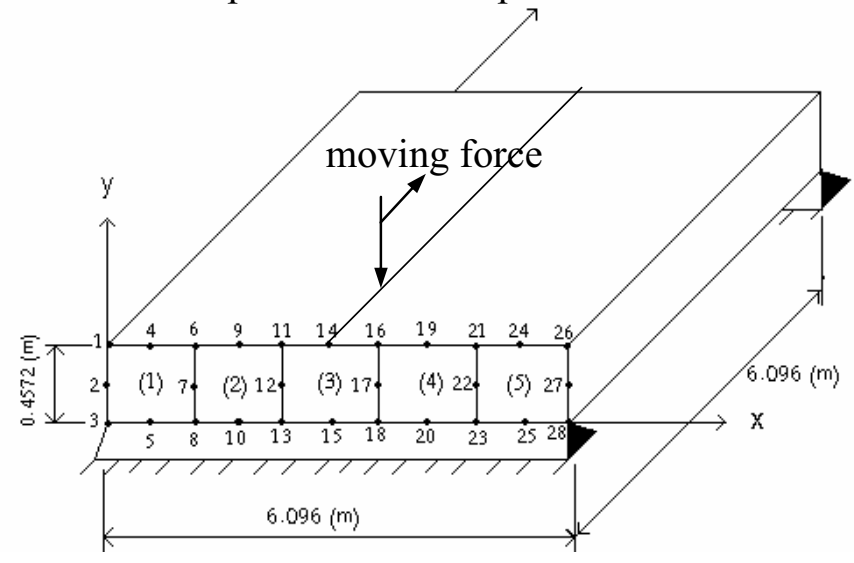

Figure (3) Geometry and finite prism idealization of two opposite edges simply supported plate.

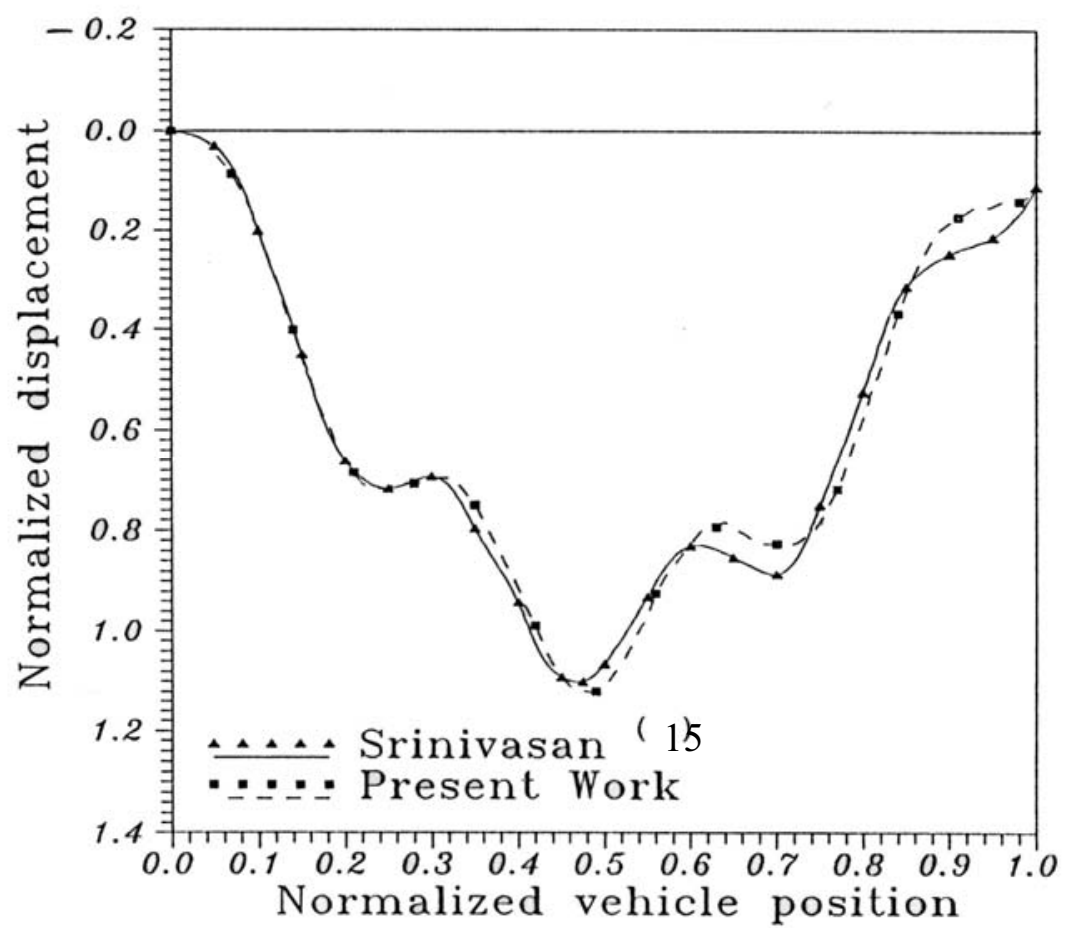

Figure (4) Normalized displacement at the center of simply supported plate. 


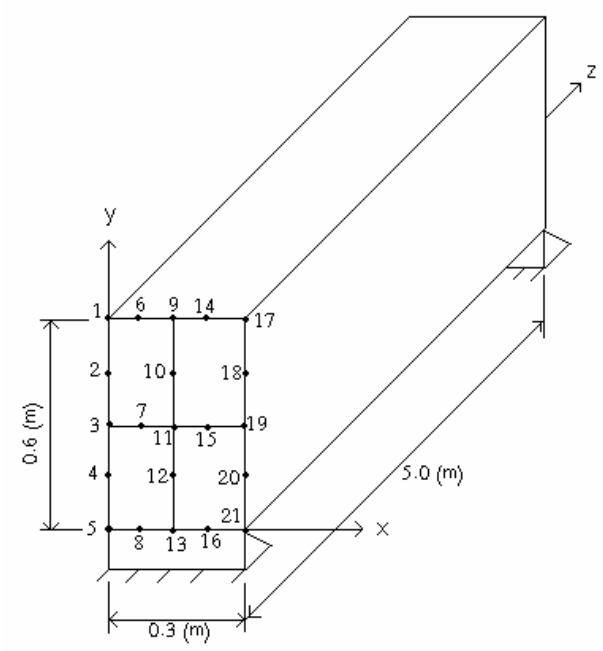

Figure (5) Geometry and finite prism idealization of simply supported beam.

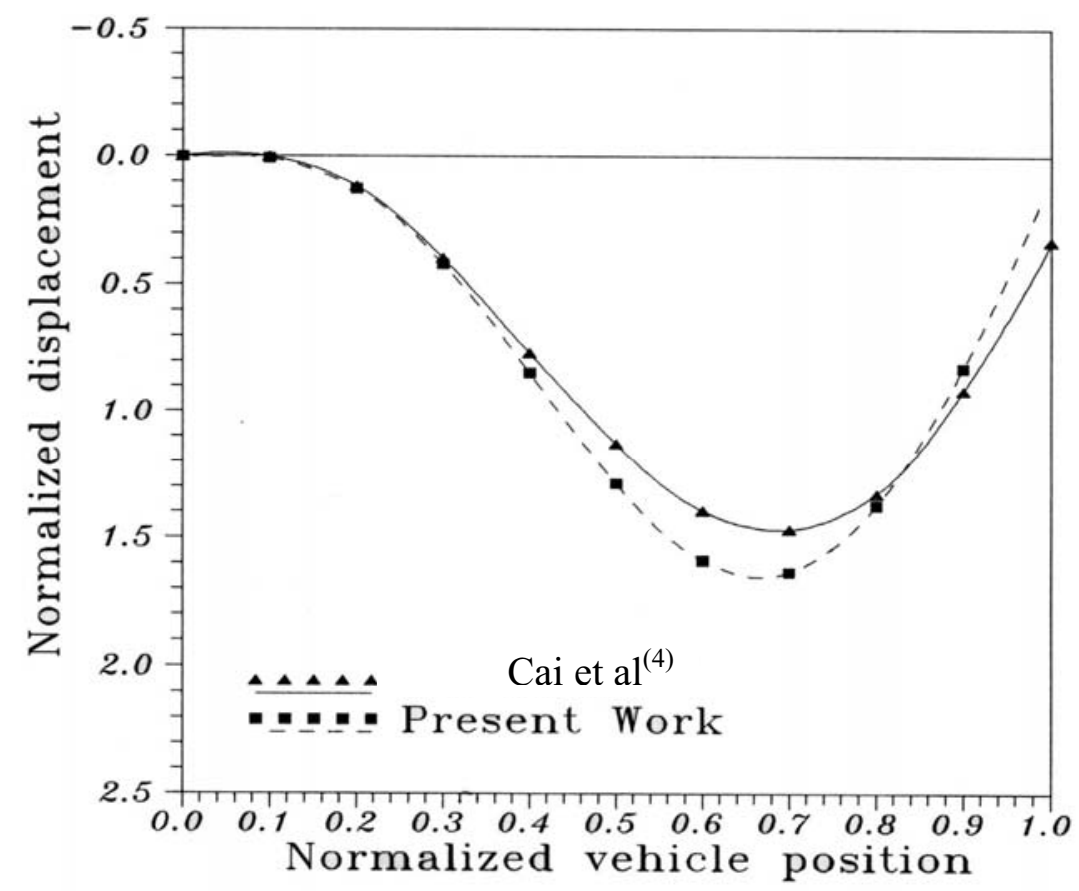

Figure (6) Normalized displacement of simply supported beam due to vehicle speed $(590.4 \mathrm{~km} / \mathrm{h})$. 


\begin{tabular}{llll} 
Al-Rafidain Engineering & Vol.14 & No.4 & 2006 \\
\hline
\end{tabular}

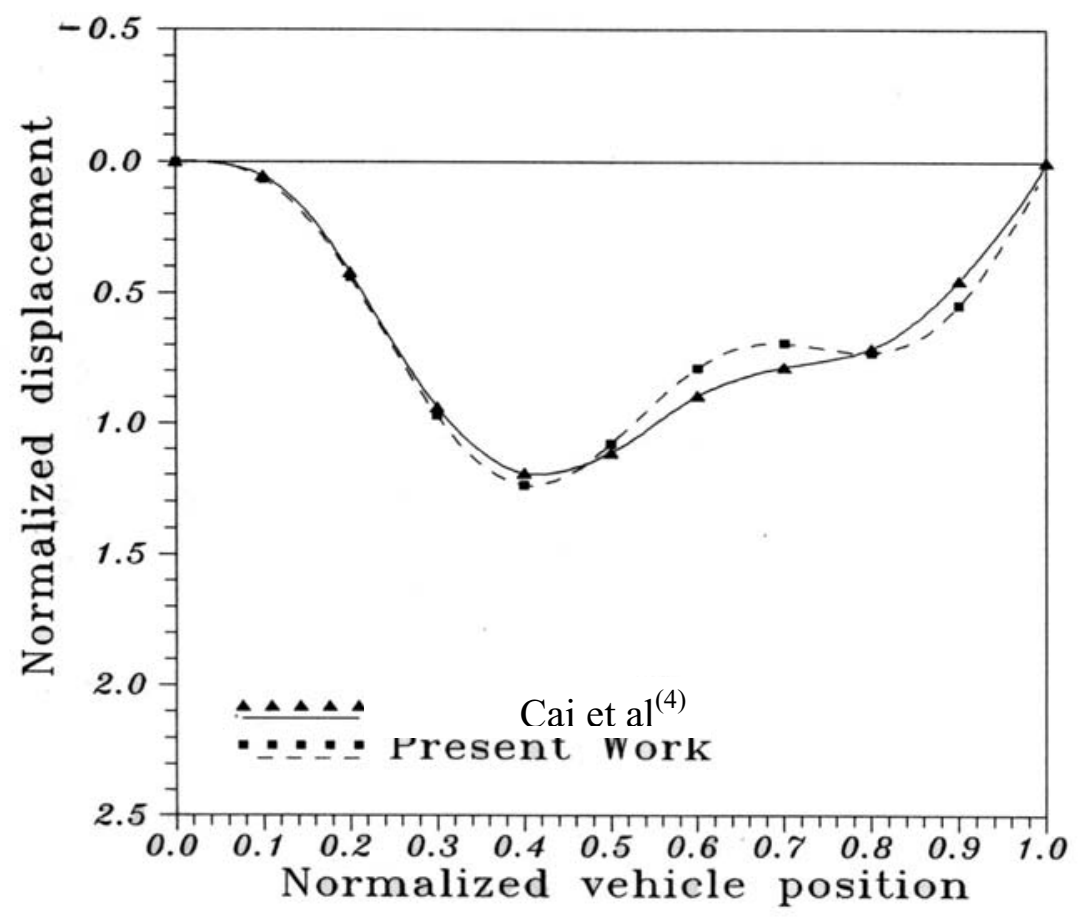

Figure (7) Normalized displacement of simply supported beam due to vehicle speed $(295.2 \mathrm{~km} / \mathrm{h})$.

\section{Dynamic analysis of deck girder bridge}

A simply supported deck girder bridge with the geometry shown in Figure (8) subjected to vehicle model moving over the central girder. The bridge crosssection is divided into 25 prism elements as shown in Figure (9). The details of the material properties and moving vehicle model is given below:

Modules of elasticity $=200000 \mathrm{MPa}$ (concrete)

Mass density $=2400 \mathrm{~kg} / \mathrm{m}^{3}$

Span length $=15 \mathrm{~m}$

Poisson's ratio $=0.2$

Vehicle weight $=200 \mathrm{kN}$

$c_{v}=69.12 \mathrm{~N} . \mathrm{sec} / \mathrm{mm}$

$k_{v}=5971.97 \mathrm{~N} / \mathrm{mm}$

vehicle speed vary from $40 \mathrm{~km} / \mathrm{h}$ to $100 \mathrm{~km} / \mathrm{h}$

Figure (10) shows the variation of the normalized static and dynamic displacements at the center of the exterior girder of the bridge with the normalized position of the vehicle moving over the central girder. The figure shows the effects of increasing the speed of the vehicle on the dynamic response of the bridge. It is clear that the dynamic response completely deviate from the static one when the speed of the vehicle get increased. 


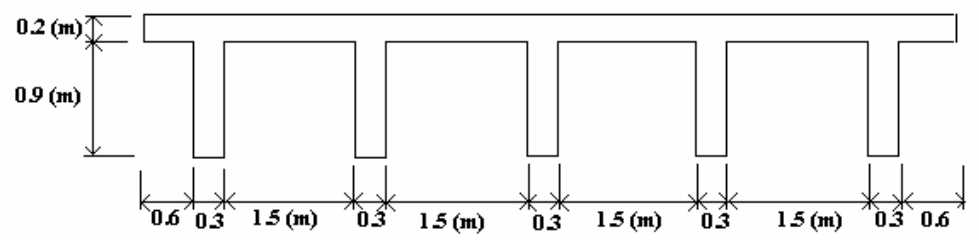

Figure (8) Details of cross-section of deck girder bridge

\begin{tabular}{|c|c|c|c|c|c|c|c|c|c|c|c|c|c|c|}
\hline 1 & 2 & 5 & 6 & 7 & 10 & 11 & 12 & 15 & 16 & 17 & 20 & 21 & 22 & 23 \\
\hline & 3 & & & 8 & & & 13 & & & 18 & & & 24 & \\
\hline & 4 & & & 9 & & & 14 & & & 19 & & & 25 & \\
\hline
\end{tabular}

Figure (9) Finite prism idealization of deck girder bridge

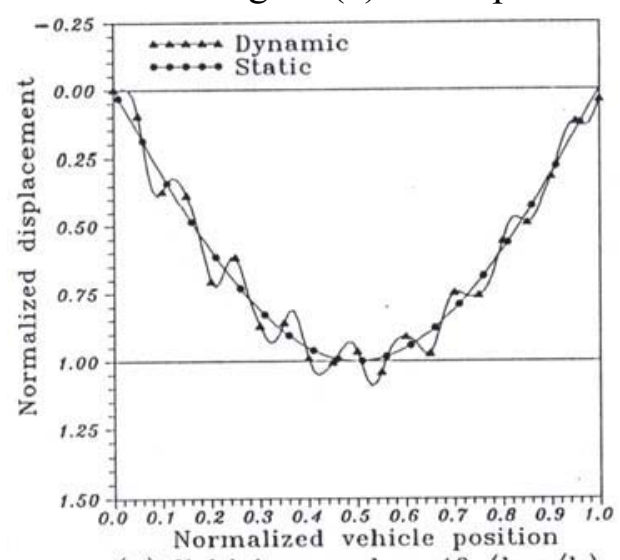

(a) Vehicle speed $=40(\mathrm{~km} / \mathrm{h})$

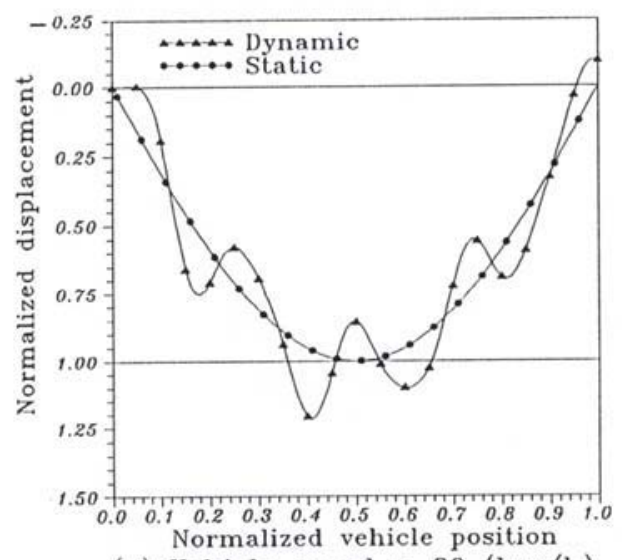

(c) Vehicle speed $=80(\mathrm{~km} / \mathrm{h})$

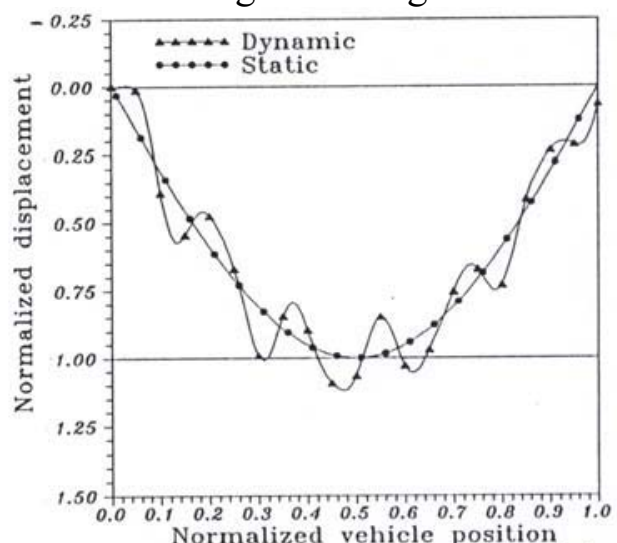

(b) Vehicle speed $=60(\mathrm{~km} / \mathrm{h})$

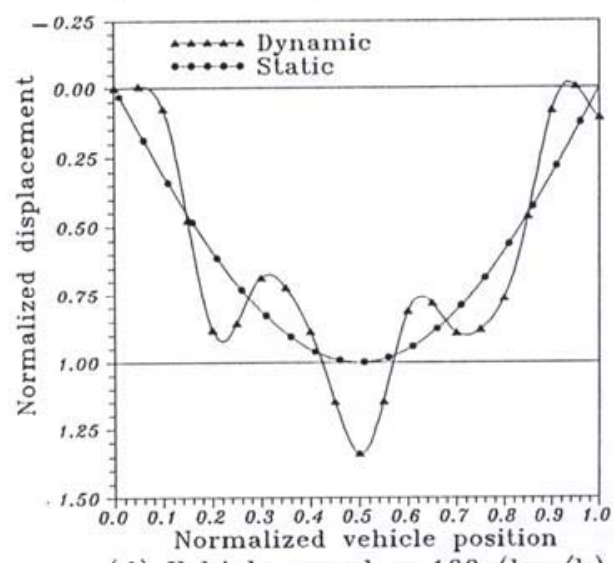

(d) Vehicle speed $=100(\mathrm{~km} / \mathrm{h})$

Figure (10) Normalized static and dynamic displacements of the center of exterior girder due to vehicle model moving over central girder 


\begin{tabular}{llll} 
Al-Rafidain Engineering & Vol.14 & No.4 & 2006 \\
\hline
\end{tabular}

\section{Conclusions}

A new model for the dynamic analysis of bridges due to moving vehicle was developed in this work.

The model is based on the coupling of the explicit solution of the equation of motion with the harmonic solution of the finite prism method.

Two different models for the vehicle are presented, these are the moving force model which is assumed to be constant during the traveling time of the vehicle along the span, and the moving vehicle model which takes into consideration the interaction between the bridge and the vehicle model. The numerical results from the developed computer code in the present study have shown good agreement with published data. The interaction of the vehicle with the bridge shows that the dynamic response of the bridge significantly affected by the speed of the vehicle.

\section{References}

1. Al-Darzi, S. Y.; "Static and Free Vibration Analysis of Bridges Using Finite Prism Method"; M.Sc. Thesis, Department of Civil Engineering, University of Mosul, Mosul, 1998.

2. Al-Ghabsha, T. S.; "Finite Prism Dynamic Analysis of Bridges"; M.Sc. Thesis, Department of Civil Engineering, University of Mosul, Mosul, 2000.

3. Blejwas, T. E., Feng, C. C. and Ayre, R. S.; "Dynamic Interaction of Moving Vehicles and Structures"; Journal of Sound and Vibration, Vol. 67, No. 4, 1979, 513-521.

4. Cai, Y., Chen, S. S., Rote, D. M. and Coffy, H. T.; "Vehicle/Guideway Interaction for High Speed Vehicles on a Flexible Guideway"; Journal of Sound and Vibration, Vol 175, No. 5, 1994, 625-646.

5. Canet, J. M., Suarez, B. and Onate, E.; "Dynamic Analysis of Structures Using a Reissner-Mindlin Finite Strip Formulation"; Computers and Structures, Vol. 31, No. 6, 1989, 967-975.

6. Chompooming, K. and Yener, M.; "The Influence of Roadway Surface Irregularities and Vehicle Deceleration on Bridge Dynamics Using the Method of Lines"; Journal of Sound and Vibration, Vol. 183, No. 4, 1995, 567-589.

7. Cook R. D.; "Concepts and Application of Finite Element Analysis"; 2nd Ed., John Wiley and Sons. Inc., New York, 1981.

8. Donea, J. and Laval, H.; "An Improved Formulation of the Parabolic Isoparametric Element for Explicit Transient Analysis"; Earthquake Engineering and Structural Dynamics, Vol. 7, 1979, 23-29.

9. Hinton, E., Rock. T. and Zienkiewics, O. C. ; "A Note on Mass Lumping and Related Processes in the Finite Element Method"; Earthquake Engineering and Structural Dynamics, Vol. 4, 1976, 245-249. 
10. Inbanathan, M. J. and Wieland, M.; "Bridge Vibrations Due to Vehicles Moving Over Rough Surface"; Journal of Structural Engineering, Vol. 113, No. 9, 1987, 1994-2008.

11. Kou, J. W. and DeWolf, J. T.; "Vibrational Behavior of Continuous Span Highway Bridge - Influencing Variables"; Journal of Structural Engineering, Vol. 123, No. 3, 1997, 333-343.

12. Mahmood, M. N.; "Explicit Dynamic Analysis of Mindlin Plates Using Finite Strip Methods"; Al - Rafidain Engineering, Vol. 6, No. 1, 1998, 1-10.

13. Mermertas, V.; "Dynamic Interaction Between the Vehicle and Simply Supported Curved Bridge Deck"; Computer Method in Applied Mechanics and Engineering, Vol. 162, 1998, 125-131.

14. Owen, D. R. J. and Hinton, E.; "Finite Element in Plasticity: Theory and Practice"; Pineridge Press Limited, Swansea, U. K., 1980.

15. Srinivasan, R. S. and Munaswamy, K.; "Dynamic Response of Skew Bridge Decks"; Earthquake Engineering and Structural Dynamics, Vol. 6, 1978, 139-156.

16. Timoshenko, S. P. and Goodier, J. N.; "Theory of Elasticity"; 3rd Ed., McGrawHill Book Company, New York, 1970.

17. Tsui, T. Y. and Ting, P.; "Stability of Transient Solution of Moderately Thick Plate by Finite Difference Method"; AIAA Journal, Vol. 9, No. 10, 1971, 20622063.

18. Weaver, W. and Johnston, P. R.; "Structural Dynamics by Finite Elements"; Prentice - Hall, Inc., New Jersey, 1987.

19. Zienkiewics, O. C. and Too, J. J. M.; "The Finite Prism in Analysis of Thick Simply Supported Bridge Boxes"; Proc. Inst. of Civil Engrs., Vol. 53, Part2, 1972, 147-172. 